\section{TEXTBOOK OF MEDICAL TREATMENT.}

Edited by D. M. Dunlop, L. S. P. Davidson and J. W. McNeE. E. \& S. Livingstone. Reprint, 1940. Price 25s.

The call for a reprint of this volume within seven months of its publication must be most gratifying to the Editors and their collaborators, and is ample proof that it has filled a gap in medical literature. Although the work suffers, like all such compilations in which many authors take part, from a certain degree of overlapping and from a varying degree of thoroughness with which the different subjects are treated, and although, in spite of its claims, it does not appear to us to be any more rationalistic or decisive in its recommendations than the average text-book on medicine, it can be recommended as a reliable guide to present-day therapeutics in certain groups of diseased conditions.

\section{THE CHEMICAL COMPOSITION OF FOODS.}

By R. A. M. CANCE, M.D., F.R.C.P., and E. M. Widpowson, B.Sc. Special Report Series of Medical Research Council, No. 235. H.M. Stat!onery Office. London. 1940. Price 4s.

In the provision of a suitable dietary for a community, in the treatment of diseased conditions by dietetic methods and in the investigation of nutritional problems an exact knowledge of the composition of the different articles of food is essential. The various forms in which the different constituents are present is also a point of fundamental importance since they are not always equally utilisable by the body and hence are not quantitatively interchangeable. Moreover, it is not sufficient to know the composition of the food in the raw state; more important is the availability of the different constituents after cooking and in the condition as consumed. It is information concerning the various points of some $\mathbf{5 5 0}$ articles of food which is supplied in the present publication. In tabular form are detailed the water content, the sugar content, the starch content and the nitrogen content as well as that of the protein, the fat and the individual salts and the calorie value and the acid-base balance of each food both in the raw and in the cooked state. The tables are duplicated, in one the amounts are expressed as grams per cent. and in the other as grams per ounce. In addition there are two lists showing the utilisability of the phosphorus and iron in the case of foods which supply these minerals. The foods are arranged in the tables alphabetically, as is so frequently done, but they are grouped according to type, e.g., cereals and cereal foods, meat, poultry and game, dairy products, fish, fruit, nuts, vegetables, sugar preserves and sweetmeats, beverages, beers, condi. ments, vegetable fats, cakes and pastries, puddings, meat and fish dishes, egg and cheese dishes, sauces and soups, which reveals the comprehensiveness of the work. It is apparent that an enormous amount of very highly skilled and at the same time laborious work was necessary to provide such an array of analyses. Indeed, as mentioned in the preface, the work has been continued uninterruptedly for over ten years and one marvels that such a wealth of information can be made available for the sum of four shillings.

\section{GREEN'S MANUAL OF PATHOLOGY.}

By H. W. C. Vines, M.A., M.D. Sixteenth Edition. pp. viii and 1166. 701 Illustrations. Baillière, Tindall \& Cox, London. 1940. Price 31s. 6d.

We welcome yet another edition of this text-book. It is a little different from other text-books on the subject because, during its revision, attempts have been repeatedly made to fit it into the student's curriculum so that men turning over from their pre-clinical to their clinical studies may find a connecting link so far as pathology goes in this book. It is a very laudable idea and meets the case adequately.

In this edition the principal alteration is that a chapter has been included on the reticuloendothelial system, followed by a chapter on the anæmias. This part has been handled very well and really brings this section of the book right up to date.

Naturally in a book of this size there are some portions which could be criticised, but taking it as a whole the book is accurate, devotes a considerable amount of space to the various sections, and gives a balanced view of modern ideas on pathology. Our opinion is that this is the best book on pathology for the medical student and is adequate for the medical practitioner and pathologist as a reference book.

\section{ST. THOMAS' HOSPITAL REPORTS.}

Vol. IV. 2nd Series. Edited by Prof. O. L..

De Wesselow and C. Max Page. Assisted by

N. R. Barrett, J. St. C. Elkington and

A. J. Wrigley. London. 1939. Price $10 \mathrm{~s}$. (or 7s. 6d. to St. Thomas' Hospital men).

This is one of the very much better numbers so far as hospital reports go. Naturally the articles vary in value, but one or two are of unusual interest. Dr. Richardson, one of the hospital registrars, has written a very good review on the male sex hormone giving a well-balanced and up-to-date analysis of its use ; and there is also a good article by Dr. W. Thomson on acetylcholine in relation to cardiac function. He shows that in seven normal individuals it produced tachycardia with sinus irregularity and a degree of a-v-heart block. He also shows that this drug had an effect on the level of the serum potassium in two patients, but is not able to draw any conclusion from this observation.

Professor Barnard, who carefully studied the pathological changes in the wall of the ductus arteriosus, shows that after the muscular contraction, œdema follows, and that probably the œdema is responsible for its final closure.

There is a very long article on the treatment of empyema by Mr. Belsey, resident assistant surgeon, but the conclusions hardly justify the length. He says that treatment of an acute empyema is continuous drainage and that the method of drainage seems to exert little influence on the prognosis.

There is quite a good detailed article by Dr. Vass on water soluble vitamins in body fluids. This is a very careful piece of work, and other laboratory workers would be well advised to read it.

As usual the book is very well got up. 